\title{
INTERFACES ENTRE POLITICAS EDUCACIONAIS, PRÁTICA PEDAGÓGICA E FORMAÇÃO HUMANA
}

\author{
INTERFACES BETWEEN EDUCATIONAL POLICIES, \\ PEDAGOGICAL PRACTICES AND HUMAN FORMATION
}

\author{
Maria Terezinha Bellanda Galuch* \\ Marta Sueli de Faria Sforni**
}

\begin{abstract}
Resumo
Este artigo objetiva analisar a perspectiva de formação defendida por documentos oficiais que orientam a Educação Básica, bem como as práticas pedagógicas que eles sugerem, apontando a relação entre uma política pública de definição curricular e a organização didática do conteúdo escolar. Os resultados mostram que a formação defendida pelos referidos documentos busca atender às demandas de mercado da sociedade atual, valorizando práticas pedagógicas voltadas para o desenvolvimento de atitudes, valores, competências e habilidades exigidas pela sociedade globalizada. Ao colocar em primeiro plano esse tipo de formação em detrimento da transmissão e apropriação dos conhecimentos disciplinares, a educação escolar diminui seu compromisso com a cultura científica, distanciando-se da função de oferecer os instrumentos simbólicos necessários ao desenvolvimento integral dos estudantes.
\end{abstract}

Palavras-chave: Prática pedagógica. Formação humana. Organização curricular.

\begin{abstract}
The present article analyzes the formation perspective found in official documents regarding Basic Education and the pedagogical practices suggested by them. It also points out the relationship between a curriculum-defining public policy and the didactic organization of what is taught in the schools. Results show that the formation proposed by the above-mentioned documents tries to attend our society's market demands with its valorization of pedagogical practices for the development of attitudes, values, competences and abilities required by the globalized society. When such formation is placed first and foremost and to the detriment of the transmission and appropriation of disciplines, school education decreases its commitment with scientific culture. In fact, it distances itself from its role in offering the symbolic instruments which are necessary for the students' integral development.
\end{abstract}

Keywords: Pedagogical practice. Human formation. Curricular organization.

\section{Introdução}

No Brasil, a partir do final da década de 1990, foram organizados e distribuídos às escolas públicas de Educação Básica os Parâmetros Curriculares Nacionais (PCN) para o Ensino Fundamental e Médio e o Referencial Curricular Nacional para a Educação Infantil (RCNEI). São ações voltadas ao estabelecimento de orientações curriculares que assegurem uma base nacional comum, nos respectivos níveis de ensino, conforme definem a Lei de Diretrizes e Bases da Educação Nacional (LDB) e o Plano Decenal da Educação (1993-2003). O volume introdutório dos PCN para as quatro primeiras séries do Ensino Fundamental reafirma a "[...] necessidade e a obrigação de o Estado elaborar parâmetros claros no campo curricular capazes de orientar as ações edu- cativas do ensino obrigatório, de forma a adequá-lo aos ideais democráticos e à busca da melhoria da qualidade do ensino nas escolas brasileiras". (BRASIL, 1997b, p. 14).

Conforme o Ministério da Educação, esses documentos não são modelos curriculares homogêneos e impositivos, já que, segundo a LDB, é facultado aos estados e municípios elaborarem suas propostas curriculares e pedagógicas. Todavia, mesmo que sejam apenas documentos orientadores, sem a obrigatoriedade de serem implantados na sua íntegra; mesmo que esses documentos não sejam lidos pela totalidade dos professores e que diretores e coordenadores pedagógicos não os adotem como guia de decisões na elaboração dos Projetos Político Pedagógicos das suas escolas; mesmo que Secretarias de Educação não os assumam

\footnotetext{
* Professora doutora da Universidade Estadual de Maringá. E-mail: galuch@bturbo.com.br

** Professora doutora da Universidade Estadual de Maringá. E-mail: martasforni@uol.com.br
} 
oficialmente, não há como desconsiderar a força que uma proposta curricular oficial exerce sobre a educação escolar. Sobre esse aspecto, Lopes (2002, p. 391) escreve:

O discurso pedagógico oficial formado pelos documentos oficiais é capaz de regular a produção, distribuição, reprodução, inter-relação e mudança dos textos pedagógicos legítimos, suas relações sociais de transmissão e aquisição e a organização de seus contextos, redefinindo as finalidades educacionais da escolarização.

Uma análise apenas do ponto de vista dos encaminhamentos didático-pedagógicos poderia nos levar a dizer que a elaboração dos Parâmetros Curriculares Nacionais significa tão somente uma medida que, sem pretender uniformizar o ensino, visa garantir que alunos de escolas públicas de diferentes regiões de um país com vasto território como o Brasil recebam uma formação com uma base comum. Isso porque, embora tais documentos sejam "[...] abertos e flexíveis, podendo ser adaptados à realidade de cada região" (BRASIL, 1997b, p. iv), apresentam a "caracterização das áreas, objetivos, organização dos conteúdos, critérios de avaliação e orientações didáticas". (BRASIL, 1997b, p. 29).

Apesar de esses documentos resultarem de um processo que envolveu a participação de diferentes instâncias da sociedade civil, acadêmica e governamental - e de se constituírem em referência para a educação brasileira -, têm recebido muitas críticas de pesquisadores da área educacional. (SILVA JR, 2002; FREITAS, 2002; CURY, 2002; LOPES, 2002; GALLO, 2004). Dentre as críticas, a principal delas consiste no fato de os Parâmetros Curriculares Nacionais serem fruto de uma política educacional marcadamente neoliberal, voltada a atender às necessidades do mercado de trabalho, tanto no que se refere à qualificação profissional como à formação de valores e atitudes concernentes à manutenção da ordem social capitalista, fundamentada na troca desigual.

Ao analisarmos os princípios teóricos que orientam os Parâmetros Curriculares Nacionais para o Ensino Fundamental e Médio e o Referencial Curricular para a Educação Infantil, percebemos que a organização desses documentos marcou o ingresso do Brasil no contexto de globalização das políticas

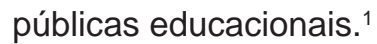

\footnotetext{
${ }^{1}$ Recorremos a uma análise de Moraes (2001), com base na qual podemos compreender que não apenas o Brasil ingressou nessas políticas. Esse fenômeno pode ser observado nos demais países da América Latina, cuja concentração de pobreza pode significar uma ameaça aos países desenvolvidos. Segundo a autora, "para confirmar a premissa basta conferir os documentos elaborados pelo Banco Mundial, na década de 1990. Confrontados com documentos de outras agências, como a CEPAL, por exemplo, ou com documentos oficiais ou oficiosos de governos nacionais, na América Latina, percebe-se uma recorrente repetição de temas e sugestões de políticas educacionais". (MORAES, 2001, p. 22).
}

Com base em quê podemos fazer tal afirmação? São documentos que se apropriam de discussões políticas e acadêmicas e de concepções de ensino e aprendizagem, resultando numa sistematização de proposta curricular amparada por uma perspectiva de formação que atende às necessidades da sociedade regulada pelo mercado. (LOPES, 2002, p. 392). A formação almejada mantém consonância com a defendida no Relatório para a UNESCO da Comissão Internacional sobre Educação para o século XXI - conhecido como Relatório Jacques Delors - para os países em desenvolvimento. Portanto, a criação desses Parâmetros e Referenciais significa que uma nova perspectiva teórico-metodológica passa a balizar os debates sobre os conteúdos escolares e os processos de ensino e aprendizagem.

É nesse contexto que este trabalho se insere, objetivando compreender a perspectiva de formação presente nos PCN e no Relatório Jacques Delors, bem como o tipo de prática pedagógica que eles sugerem.

Nos Parâmetros Curriculares Nacionais para a Educação Básica - Ensino Fundamental e Médio - a ênfase recai sobre uma formação voltada, dentre outros, para o desenvolvimento do pensamento crítico, da criatividade, da capacidade de analisar e interferir na realidade, da capacidade de participar das decisões político-sociais, da capacidade de o aluno permanecer em constante processo de aprendizado e da sua competência de encontrar soluções para problemas de diferentes naturezas, conseguindo transpor esse aprendizado para situações sociais e do trabalho. Ao mesmo tempo, há claras orientações para que a escola se empenhe em garantir uma Educação que tenha como objetivo desenvolver nos alunos o espírito de solidariedade, o saber viver juntos, o respeito e a tolerância aos diferentes e, sobretudo, possibilite uma formação voltada para a cidadania.

Por que essas capacidades e não outras? Não se trata de uma formação contraditória? Como formar sujeitos competitivos e, ao mesmo tempo, solidários?

Compreender porque são eleitas essas capacidades como foco da educação escolar na atualidade pressupõe o entendimento da relação existente entre escola e sociedade, ou seja, a organização do processo de produção é a chave para o entendimento da formação que se espera que a escola ofereça. Portanto, se pretendemos desvelar a formação requerida, antes devemos compreender as leis que regulam a sociedade na qual a escola está inserida. 


\section{A organização do mundo do trabalho na atuali- dade e demandas de formação}

A partir da década de 1970, passamos a viver uma forma de organização da produção que se confronta diretamente com a rigidez do taylorismo/ fordismo: o toyotismo - flexível à demanda do mercado.

A acumulação flexível [...] é marcada por um confronto direto com a rigidez do fordismo. Ela se apóia na flexibilidade dos processos de trabalho, dos mercados de trabalho, dos produtos e padrões de consumo. Caracteriza-se pelo surgimento de setores de produção inteiramente novos, novas maneiras de fornecimento de serviços financeiros, novos mercados e, sobretudo, taxas altamente intensificadas de inovação comercial, tecnológica e organizacional. A acumulação flexível envolve rápidas mudanças dos padrões de desenvolvimento desigual, tanto entre setores como entre regiões geográficas, criando, por exemplo, um vasto movimento no emprego no chamado "setor de serviços", bem como conjuntos industriais completamente novos em regiões até então subdesenvolvidas. (HARVEY, 2001, p. 140).

Nessa forma de organização fundamentada na flexibilidade, tanto dos processos de trabalho envolvidos na produção como dos produtos e padrões de consumo, os trabalhadores não mais se fixam numa única tarefa, necessitando buscar soluções para múltiplos problemas cuja solução antes cabia apenas a dirigentes. Se as vendas caem, os funcionários - agora denominados de colaboradores são convocados a alavancá-las mediante esforços e criatividade próprios. Desse modo, não raro, encontramos cartazes em empresas de diferentes setores atribuindo o título de "vendedor do mês" ou "gerente do mês" àquele "colaborador" que superou a meta de vendas estabelecida pela empresa. Todavia, trata-se de um "título" tão difícil de ser preservado, quanto o é a preservação do próprio emprego. Para manter-se empregado na produção em bases toyotistas, marcada pela multifuncionalização da mão de obra, os sujeitos precisam apresentar capacidades para tomar decisões e trabalhar em equipe, devem ter conhecimentos de informática, dominar mais de uma língua, dentre outras. São capacidades que os tornam empregáveis num mundo em que a informatização do processo produtivo fez do emprego algo cada vez mais raro. No que se refere à flexibilização dos produtos, enquanto na produção rígida os modelos permaneciam no mercado por um longo período, sendo considerados tradicionais, na produção toyotista, que busca atender mercados segmentados, a novidade e o diferente tornam-se questões de ordem, apesar de muitas vezes se apresentarem apenas como mudanças em alguns aspectos do produto: cor, formato, etc. Para o sucesso na criação de novos produtos, é preciso que o trabalhador es- teja constantemente atualizado, o que implica ter o domínio de novas tecnologias, novos idiomas, novos processos de produção, etc. Isso inclui desde aqueles que atuam nos processos de criação e produção, como aqueles que atuam nos setores de marketing e vendas.

Como a produção flexível sem "consumidores flexíveis", isto é, sem sujeitos receptivos à efemeridade das mercadorias, não resultaria em venda, os sujeitos são, desde a tenra infância, cuidadosamente educados para gostarem das novidades, identificarem-se com o último lançamento, aderirem às modas efêmeras. Entra, então, o poder da propaganda para a indução de necessidades. Se antes a qualidade do produto garantia a sua venda, agora é a propaganda que faz esse papel, passando a ser a "alma do negócio". Nesse sentido, as palavras "novo" e "novidade" aparecem como um dos principais argumentos para a divulgação de um produto, independentemente de ser alimento, peça de vestuário, automóvel, eletrodoméstico, medicamento, aparelho eletrônico, livro, ou a própria juventude prometida pelo uso de produtos de beleza inovadores.

Nesse contexto, cria-se em cada "cidadão" a necessidade de ter mais do que precisa, bem como a certeza de que felicidade é sinônimo de compras. Observa-se, portanto, uma "adesão voluntária" dos sujeitos a uma forma de ser e agir perante o consumo, tal como aponta Marcuse (1979). Com a flexibilização do processo produtivo surgem novos setores de produção e novos mercados, num mundo cada vez mais globalizado. Nessa nova forma organizacional, a produção torna-se cada vez mais enxuta: menos mão de obra, menos estoque, terceirização e mudança de grandes conjuntos industriais para regiões até então subdesenvolvidas. (GALUCH, 2004). Para o atendimento dessa forma de organização da atividade produtiva, são criados novos tipos de contrato de trabalho como, por exemplo, os temporários e os serviços terceirizados, bem como se diminui a jornada de trabalho mediante a redução de salários. Esses contratos passam a ser regulados por acordos celebrados diretamente entre os envolvidos, sem a mediação de sindicatos de categorias que, cada vez mais, vão perdendo força como representantes da classe trabalhadora.

Interessante observar que nesse cenário o setor de serviços tem crescido vertiginosamente. Não apenas a prestação de serviços terceirizados e o fornecimento de peças e acessórios para grandes empresas industriais, mas serviços na área de alimentação, entretenimento e eventos em geral. Com essas novas formas de trabalho, criam-se as condições objetivas para novas formas de lazer e de convívio social. Por exemplo, com o crescimento de empresas de eventos, cresce o número de sujeitos que "sentem" necessidade de realizar grandes 
festas para comemorar formaturas, casamentos, batizados, aniversários, dentre outras datas, como um meio de demonstração pública de afeto. Assim, as comemorações passam a ser um "palco" para a exibição da vida privada e poder, perdendo, muitas vezes, o seu significado original. Como explica Harvey (2001, p. 148), vivemos a estética pósmoderna, que celebra a diferença, a efemeridade, o espetáculo, a moda e a mercadificação de formas culturais.

A competição entre as empresas exige de patrões e empregados a constante atualização no sentido de garantir a capacidade para solucionar problemas, trabalhar em equipe e agir sob pressão. Diante da escassez de oportunidades de emprego, a competição transforma-se na marca das relações entre os próprios sujeitos, ganhando, a cada dia, requinte de individualismo. Como alcançar o posto de "vendedor do mês" se o sujeito não vencer a competição com os demais? Como não ser individualista num contexto em que os empregos são ameaçados pela substituição do homem pela máquina ${ }^{2}$ ou por jovens trabalhadores com formação mais "adequada", dispostos a aceitarem salários inferiores?

Enquanto a produção taylorista/fordista necessitava de sujeitos disciplinados, com capacidades para a execução de tarefas repetitivas, a produção de base toyotista requer sujeitos que executam múltiplas tarefas e encontrem soluções para diferentes problemas. Todavia, são mudanças substanciais no processo de produção, mas não na lógica objetiva das relações sociais da sociedade, quer dizer, os princípios que fundamentam a sociedade capitalista - a produção para o lucro - não foram alterados.

Essas mudanças exigidas na contemporaneidade, em relação à Educação, geralmente, são apontadas como um avanço da sociedade em direção a uma formação superior que teria por finalidade promover o desenvolvimento dos sujeitos. Entretanto, essas novas capacidades exigidas do trabalhador são decorrentes das transformações na forma de organização do processo produtivo e não porque se almeja uma formação com vistas à humanização. É certo que as capacidades requeridas na atualidade são diferentes das capacidades exigidas do trabalhador no momento em que a produção se mecanizou e no momento em que a produção se guiou pelos princípios tayloristas/fordistas. Essas diferenças, muitas vezes, conduzem à interpretação de que na produção flexível - toyotista as capacidades exigidas são mais humanizadas,

\footnotetext{
${ }^{2}$ Observa-se que a máquina substitui o homem tanto na realização de trabalhos pesados, como na realização de trabalhos que exigem coordenação motora fina e acuidade visual, bem como no atendimento ao cliente/usuário, dentre outros, por meio de caixas eletrônicos, sistemas on-line e gravação de voz que orienta à tecla referente ao serviço desejado.
}

porque demandam maior desempenho intelectual. (PALANGANA, 1998). Os objetivos da formação, porém, não se diferem daqueles postulados pela produção taylorista/fordista, pois ambas as formas de produzir buscam uma formação capaz de tornar os sujeitos adaptáveis às necessidades da sociedade que, por sua vez, continua regulada por relações entre classes antagônicas, sem a preocupação com o desenvolvimento integral de todos os seres humanos. Interessante observar que, nesse contexto, a Educação se transforma na panaceia para os problemas enfrentados pelos sujeitos, diante das novas exigências impostas pelo mercado. Defende-se que a escola deve ser renovada, ou seja, romper com antigas metodologias, conteúdos e objetivos, com vistas ao desenvolvimento de competências necessárias ao mundo em constante mudança. Apesar de o discurso em relação ao desenvolvimento de competências e habilidades ser geral para todos, para alguns, considera-se necessário uma Educação que os capacite para postos de comando, cujas atividades exigem alto nível de aprendizagem; para outros - a maioria -, defende-se uma Educação que ofereça apenas o suficiente para o ingresso e permanência no mercado de trabalho. Sobre questão, a reflexão de Moraes (2001, p. 8) é esclarecedora:

De fato, o elevado grau de competitividade ampliou a demanda por conhecimentos e informações e, em decorrência, a educação foi eleita estratégica para fazer face à velocidade das mudanças. Se o mundo virou pelo avesso, a educação deve acompanhá-lo na reviravolta. A escola tradicional, a educação formal, as antigas referências educacionais, tornam-se obsoletas. É preciso, agora, elaborar uma nova pedagogia, um projeto educativo de outra natureza. O discurso é claro: não basta apenas educar, é preciso assegurar o desenvolvimento de "competências"(transferable skills), valor agregado a um processo que, todavia, não é o mesmo para todos. Para alguns, exige níveis sempre mais altos de aprendizagem, posto que certas "competências" repousam no domínio teórico-metodológico que a experiência empírica, por si só, é incapaz de garantir. Para a maioria, porém, bastam as "competências" no sentido genérico que o termo adquiriu hoje em dia, e que permitem a sobrevivência nas franjas do núcleo duro de um mercado de trabaIho fragmentário, com exigências cada vez mais sofisticadas e níveis de exclusão jamais vistos na história.

Além de responder pela formação de competências para adaptação do sujeito ao mercado de trabalho, a Educação é chamada para responder aos problemas gerados por esse mesmo desenvolvimento, ou seja, é preciso lidar com a outra face da moeda, na qual estão impressas as marcas da exclusão gerada pela manutenção das relações sociais de produção. 


\section{Parâmetros Curriculares Nacionais e Relatório Jacques Delors: um olho no desenvolvimento das forças produtivas, outro na manutenção das relações sociais}

Face às exigências pós-modernas de globalização do processo produtivo que exigem inovação e competitividade das empresas, passa-se a exigir um trabalhador com as características acima apontadas. Sabe-se, no entanto, que o desenvolvimento de forças produtivas que permitiu a transformação na forma de se produzir mercadorias no interior da sociedade capitalista não resulta, necessariamente, em melhores condições de vida para a população, pois, mantidas as relações sociais de produção, mantêm-se as diferenças na participação de cada indivíduo no desenvolvimento atingido pela humanidade. Assim,

[...] alguns enriquecem como executivos das novas empresas ou fornecedores das mesmas, outros conseguem um ganha-pão como empregados ou terceirizados, mas muitos ficam desempregados, à espera de uma oportunidade, e outros são excluídos de qualquer participação normal na vida econômica, ficando relegados a atividades precárias. (SINGER, 2004, p. 9).

Essa realidade não é desconsiderada pelos organismos internacionais, afinal ela pode representar riscos para a estabilidade social. Nesse sentido, é preciso pensar também em uma formação que esteja atenta a essas novas configurações das relações sociais.

É com um olho na formação daqueles que poderão ingressar no mundo do trabalho e outro na formação daqueles que ficarão à margem dele que o Relatório Jacques Delors inicia a sua explicação sobre o desafio da Educação na atualidade: ser trabalhador e cidadão.

Com os progressos actuais e previsíveis da ciência e da técnica, e a importância crescente do cognitivo e do imaterial na produção de bens e serviços, todos devemos convencer-nos das vantagens de repensar o lugar ocupado pelo trabalho e seus diferentes estatutos, na sociedade de amanhã. Exactamente para poder criar esta nova sociedade, a imaginação humana deve ser capaz de se adiantar aos avanços tecnológicos, se quisermos evitar o aumento do desemprego, a exclusão social ou as desigualdades de desenvolvimento.

Por todas estas razões, parece impor-se, cada vez mais, o conceito de Educação ao longo de toda a vida, dadas as vantagens que oferece em matéria de flexibilidade, diversidade e acessibilidade no tempo e no espaço. É a idéia de educação permanente que deve ser repensada e ampliada. É que, para lá das necessárias adaptações relacionadas com as alterações da vida profissional, ela deve ser encarada como uma construção contínua da pes- soa humana, dos seus saberes e aptidões, da sua capacidade de discernir e agir. Deve levar cada um a tomar consciência de si próprio e do meio ambiente que o rodeia, e a desempenhar o papel social que the cabe enquanto trabalhador e cidadão. (DELORS, 1996, p. 17).

O Relatório deixa claro o papel da Educação numa sociedade marcada pela divisão de classe e pela desigualdade social:

A educação não pode, por si só, resolver os problemas postos pela ruptura (onde for o caso) dos laços sociais. Espera-se, no entanto, que contribua para o desenvolvimento do querer viver juntos, elemento básico da coesão social e da identidade nacional. (DELORS, 1996, p. 59).

Diferentemente das pedagogias críticas que viam na Educação a possibilidade de instrumentalizar as classes trabalhadoras visando a transformação social (SAVIANI, 2007), o Relatório Jacques Delors a coloca a serviço da coesão social. Esperase que a Educação ajude sujeitos, grupos sociais e países a buscarem o "querer viver juntos", mesmo que os laços sociais estejam rompidos, mesmo que a desigualdade social esteja presente.

Para o alcance desse objetivo, propõe-se a organização do ensino pautado em quatro pilares: aprender a conhecer; aprender a fazer; aprender a viver juntos; e aprender a ser. Se o desenvolvimento das forças produtivas exige um trabalhador flexível, é preciso que a escola o ensine a aprender a conhecer e continuar aprendendo ao longo de toda a vida. Se a produção flexível exige capacidades e habilidades para resolver problemas e trabalhar em grupo, a escola deve incluir entre as suas aprendizagens não a formação profissional em si, mas o "aprender a fazer", de modo que os estudantes estejam aptos a qualquer tipo de trabalho. Se o mundo do trabalho não resolve ou até acentua as "rupturas dos laços sociais", é necessário que na escola se aprenda a viver juntos, de modo a serem minimizados os conflitos sociais. Se é necessário que os sujeitos tenham mais autonomia e se responsabilizem por si mesmos, a escola deve influenciar no desenvolvimento da personalidade dos sujeitos, de modo que eles aprendam a ser sujeitos autônomos e responsáveis e, sobretudo, que acreditem nessa possibilidade.

$\mathrm{Na}$ introdução do Relatório, fica explícito que a ênfase dessa perspectiva de formação está no aprender a ser. Nas palavras dos próprios autores:

[...] a modificação profunda dos quadros tradicionais da existência humana, coloca-nos perante o dever de compreender melhor o outro, de compreender melhor o mundo. Exigências de compreensão mútua, de entreajuda pacífica e, porque não, de harmonia são, precisamente, os valores de que o mundo mais carece. 
Esta tomada de posição levou a Comissão a dar mais importância a um dos quatro pilares por ela considerados como as bases da educação. Tratase de aprender a viver juntos, desenvolvendo o conhecimento acerca dos outros, da sua história, tradições e espiritualidade. E a partir daí, criar um espírito novo que, graças precisamente a esta percepção das nossas crescentes interdependências, graças a uma análise partilhada dos riscos e dos desafios do futuro, conduza à realização de projetos comuns ou, então, a uma gestão inteligente e apaziguadora dos inevitáveis conflitos. (DELORS, 1996, p. 18-19).

As pedagogias críticas também reconheciam a presença dos conflitos sociais, mas, diante deles, propunham que a Educação fosse fonte de esclarecimento sobre os fatores que os originam. No Relatório Jacques Delors propõe-se que sejam buscadas saídas apaziguadoras para os conflitos, mediante o desenvolvimento de atitudes e valores de solidariedade, respeito e cidadania, aliado à realização de projetos comuns, nos quais as diferenças sejam respeitadas e, obviamente, mantidas. O Relatório mostra que a sociedade atual tende a enfatizar o "espírito de competição" e o "sucesso individual", resultando em tensão entre ricos e pobres. Para reduzir o perigo de conflitos entre os mais e os menos favorecidos economicamente, recomenda-se:

Que fazer para mudar a situação? A experiência mostra que, para reduzir o risco, não basta pôr em contato e em comunicação membros de grupos diferentes (através de escolas comuns a várias etnias ou religiões, por exemplo). Se, no seu espaço comum, estes diferentes grupos já entram em competição, ou se o seu estatuto é desigual, um contacto deste gênero pode, pelo contrário, agravar ainda mais as tensões latentes e degenerar em conflitos. Pelo contrário, se este contacto se fizer num contexto igualitário, e se existirem objectivos e projectos comuns, os preconceitos e a hostilidade latente podem desaparecer e dar lugar a uma cooperação mais serena e até amizade.

Parece, pois, que a educação deve utilizar duas vias complementares. Num primeiro nível, a descoberta progressiva do outro. Num segundo nível, e ao longo de toda vida, a participação em projectos comuns, que parece ser um método eficaz para evitar ou resolver conflitos latentes (DELORS, 1996, p. 84).

O Relatório destaca que essa perspectiva de formação deve inspirar e orientar as reformas educativas, tanto na elaboração de programas como na definição de políticas pedagógicas. Isso aconteceu com as políticas educacionais brasileiras, a partir da década de 1990, mediante a elaboração da Lei de Diretrizes e Bases da Educação Brasileira (LDB) (Lei no 9.394/1996) e dos Parâmetros Curriculares Nacionais nos quais essas concepções foram claramente incorporadas.
No artigo segundo da LDB encontra-se a seguinte afirmação:

A Educação, dever da família e do Estado, inspirada nos princípios de liberdade e nos ideais de solidariedade humana, tem por finalidade o pleno desenvolvimento do educando, seu preparo para o exercício da cidadania e sua qualificação para o trabalho. (BRASIL, 1996).

Os "quatro pilares" expostos no Relatório Jacques Delors se expressam nos Parâmetros Curriculares Nacionais das séries iniciais, destacando-se a ideia segundo a qual a educação escolar deve ser concebida de forma mais ampla, contemplando não apenas aprendizagens conceituais, mas também atitudinais e procedimentais. A passagem abaixo, constante nos Parâmetros Curriculares Nacionais Meio Ambiente/Saúde, de $1^{\mathrm{a}}$ à $4^{\mathrm{a}}$ série, exemplifica essa afirmação:

O professor deve, sempre que possível, possibilitar a aplicação dos conhecimentos à realidade local, para que o aluno se sinta potente, com uma contribuição a dar, por pequena que seja, para que possa exercer sua cidadania desde cedo. E, a partir daí, perceber como mesmo os pequenos gestos podem ultrapassar limites temporais e espaciais, como às vezes, um simples comportamento ou um fato local pode se multiplicar ou se estender até atingir dimensões universais. Ou ainda, como situações muito distantes podem afetar seu cotidiano. (BRASIL, 1997a, p. 55).

Os "quatro pilares" são citados no volume introdutório dos Parâmetros Curriculares Nacionais para as séries finais do Ensino Fundamental como aprendizagens a serem promovidas pela educação escolar. No que se refere à organização curricular, incluir a formação de atitudes e valores com vistas ao aluno aprender a conviver, implica mudanças fundamentais no conteúdo escolar:

A escola, ao tomar para si o objetivo de formar cidadãos capazes de atuar com competência e dignidade na sociedade, buscará eleger, como objeto de ensino, conteúdos que estejam em consonância com as questões sociais que marcam cada momento histórico, cuja aprendizagem e assimilação são as consideradas essenciais para que os alunos possam exercer seus direitos e deveres. (BRASIL, 1998b, p. 43-44).

Outro aspecto nessa perspectiva de formação que sugere modificação no conteúdo escolar referese à aprendizagem de competências e habilidades necessárias ao mundo do trabalho:

Hoje em dia não basta visar a capacitação dos estudantes para futuras habilitações nas especializações tradicionais. Trata-se de ter em vista a formação dos estudantes para o desenvolvimento de suas capacidades, em função de novos saberes que se produzem e que demandam um novo tipo de profissional. 
Essas relações entre conhecimento e trabalho exigem capacidade de iniciativa e inovação e, mais do que nunca, a máxima "aprender a aprender" parece se impor à máxima "aprender determinados conteúdos”. (BRASIL, 1998b, p. 44).

Nos PCN de Matemática, essa preocupação também é ressaltada:

Em função do desenvolvimento das tecnologias, uma característica contemporânea marcante no mundo do trabalho, exigem-se trabalhadores mais criativos e versáteis, capazes de entender o processo de trabalho como um todo, dotados de autonomia e iniciativa para resolver problemas em equipe e para utilizar diferentes tecnologias e linguagens (que vão além da comunicação oral e escrita). Isso faz com que os profissionais tenham de estar num contínuo processo de formação e, portanto, aprender a aprender torna-se cada vez mais fundamental. (BRASIL, 1998a, p. 27).

Observa-se, portanto, que os conteúdos formais das diferentes disciplinas escolares passam a dividir espaço com outros conteúdos, temas sociais ou metodologias que trazem em si a característica de formação desejada. Ao se referir à relação entre aprendizagem escolar e trabalho na introdução aos Parâmetros Curriculares Nacionais do $3^{\circ}$ e $4^{\circ}$ ciclos do Ensino Fundamental consta:

[...] é necessária a utilização de metodologias capazes de priorizar a construção de estratégias de verificação e comprovação de hipóteses na construção do conhecimento, a construção de argumentação capaz de controlar os resultados desse processo, o desenvolvimento do espírito crítico capaz de favorecer a criatividade, a compreensão dos limites e alcances lógicos das explicações propostas. (BRASIL, 1998b, p. 44).

Para uma formação dessa natureza, as diferentes disciplinas devem dar a sua contribuição:

[...] o ensino de Matemática prestará sua contribuição na medida em que forem exploradas metodologias que priorizem a criação de estratégias, a comprovação, a justificativa, a argumentação, o espírito crítico, e que favoreçam a criatividade, o trabalho coletivo, a iniciativa pessoal e a autonomia advinda do desenvolvimento da confiança na própria capacidade de conhecer e enfrentar desafios. (BRASIL, 1997c, p. 26).

Apesar de se observar a forte presença das orientações internacionais, tanto na Lei de Diretrizes e Bases da Educação Nacional (LDB no 9.394/96) como nos Parâmetros Curriculares Nacionais para o ensino fundamental e médio, nos Parâmetros Curriculares Nacionais a ideia de adaptação dos sujeitos às necessidades do capital não está tão explícita, tampouco a preocupação exacerbada com a manutenção da ordem social tal como pode ser observado no Relatório Jacques Delors. Isso não significa que esse objetivo não se faz presente nesses documentos norteadores da organização curricular da Educação Básica. Dentre outros fatores, talvez isso esteja relacionado ao fato de que, no Brasil, na elaboração dos Parâmetros Curriculares Nacionais, foi necessário o diálogo com as pedagogias críticas que buscaram orientar a prática educativa na década de 1980, como a Pedagogia Crítico-Social dos Conteúdos e a Pedagogia Histórico-Crítica. Essas pedagogias que se fundamentam em pressupostos do materialismo histórico estavam fortemente presentes nos cursos de formação de professores e nos debates acadêmicos desse período. Assim, alguns termos dessas teorias foram apropriados pelos Parâmetros Curriculares Nacionais, mas os seus significados foram reconfigurados, adaptando-se às políticas internacionais. Isso gera dificuldade para a compreensão da perspectiva de formação presente nesses documentos, sem que se busque o contexto de sua elaboração.

\section{Parâmetros Curriculares Nacionais e Relatório Delors: práticas pedagógicas decorrentes}

As orientações contidas em documentos oficiais podem não resultar automaticamente em práticas pedagógicas, mas em última instância indicam a direção para a elaboração dos Projetos Político Pedagógicos das escolas, do currículo dos cursos de formação de professores e, consequentemente, acabam indicando formas de encaminhamento da ação docente na Educação Básica. Nesse sentido, cabe-nos buscar compreender como essas orientações $^{3}$ têm influenciado as práticas educativas, ou seja, quais as implicações dessas orientações na sala de aula.

O que é revelador da prática pedagógica? Dentre outros meios, podemos eleger como objeto de análise os livros didáticos aprovados pelo MEC, uma vez que esse recurso, em muitos casos, acaba se constituindo no próprio currículo da escola. ${ }^{4}$ Além disso, os livros são avaliados pelo Programa Nacio-

\footnotetext{
${ }^{3}$ É importante destacar que os PCN não são os únicos documentos que orientam a Educação Básica brasileira. Amparados no artigo 26 da LDB, que garante aos estados e municípios a liberdade para elaboração de propostas curriculares próprias, desde que respeitada uma base nacional comum, muitos estados elaboraram suas próprias diretrizes curriculares, em alguns casos, inclusive, contrapondo-se à concepção educacional presente nos PCN. O mesmo ocorreu em vários municípios brasileiros que elaboraram propostas curriculares próprias, nas quais afirmam organizar o trabalho educativo tendo por base referenciais teórico-metodológicos que divergem daqueles assumidos pelos PCN. Por exemplo, há redes de ensino ou escolas que anunciam em sua proposta curricular ou em seu Projeto Político-Pedagógico que se fundamentam na Pedagogia Histórico-Crítica e na Abordagem Histórico-Cultural.

${ }^{4}$ Por meio dos livros didáticos, os PCN acabaram se constituindo no currículo em ação de muitas escolas, em alguns casos, contrariando o próprio currículo prescrito. (GIMENO SACRISTÁN, 2000).
} 
nal de Livros Didáticos (PNLD) sob critérios que adotam os mesmos princípios orientadores dos Parâmetros Curriculares Nacionais. (SFORNI; CASCONE, 2010). Podemos, ainda, tomar como fonte práticas pedagógicas veiculadas em periódicos destinados a orientar a ação de professores na Educação Básica. Um deles é a Revista Nova Escola, que publica na seção "Sala de aula" matérias referentes ao trabalho docente, incluindo exemplos de ações bem sucedidas e sequências didáticas para diferentes áreas do conhecimento e séries, cujos exemplares chegam às escolas localizadas em lugares mais afastados do Brasil, além de estar disponível on-line.

Como neste artigo nosso objetivo não é proceder à análise de livros didáticos, tampouco avaliar as publicações da Revista Nova Escola, mas buscar elementos que possam revelar as interfaces entre políticas educacionais, prática pedagógica e formação, nos limitaremos a refletir sobre um item de um livro didático de História e Geografia para a $4^{a}$ série do Ensino Fundamental (CASTRO, 2004) e uma proposta de atividade de Geografia publicada pela Revista Nova Escola. O livro didático faz parte de uma coleção que está entre as recomendadas pelo Guia de Livros Didáticos $-1^{\mathrm{a}}$ a $4^{\mathrm{a}}$ série. Esse Guia - elaborado pelo PNLD - tem como objetivo orientar os professores na escolha do livro didático a ser adotado pela escola. Um dos aspectos avaliados por esse Guia é a presença de conteúdos que valorizam a formação para o exercício da cidadania. Sobre a coleção da qual faz parte o livro didático acima citado, o Guia destaca como um dos aspectos positivos desse material didático a construção da cidadania. Segundo o Guia:

A construção da cidadania é privilegiada, ressaltando-se o respeito à diversidade cultural e às diferenças entre povos e membros da comunidade. São destacados hábitos, atitudes e comportamentos voltados à formação de cidadãos. [...] As atividades em grupos reforçam a cooperação, a boa convivência e o respeito mútuo. (BRASIL, 2002, p. 219-220).

No item "Nosso povo, nossa história", da unidade 1 de Geografia, intitulada "O Brasil, nosso país", o livro apresenta um texto versando sobre a ocupação territorial do Brasil, as transformações dela decorrentes e a diversidade cultural mediante a extensão territorial do Brasil. Para ilustrar que "essa diversidade se manifesta no modo de vida das pessoas nos vários lugares do país" (CASTRO, 2004, p. 153), apresenta quatro imagens: a primeira delas retrata "baianas vendendo comidas típicas"; a segunda mostra "seringueiros na extração de látex"; a terceira apresenta "trabalhadores da indústria de alimentos"; e a quarta imagem refere-se a "índios Xavante pescando no rio Xingu". Acompanha a apresentação das quatro imagens ora citadas a seguinte frase:
"Essa diversidade é uma grande riqueza. E cabe a nós, cidadãos brasileiros, valorizá-la e preservá-la". (CASTRO, 2004, p. 154).

Em seguida, propõe que os alunos, em grupos, reflitam sobre a afirmação: "A diversidade social e cultural é uma grande riqueza", orientando-se pelas questões abaixo:

- Vocês concordam com essa afirmação? Por
quê?
- Qual a importância de valorizarmos e respeitar-
mos tradições e costumes diferentes dos nossos?
- A diversidade cultural existente no Brasil é respei-
tada? Justifiquem a resposta com exemplos.
- No Brasil há discriminação social? Dêem exem-
plos. (CASTRO, 2004, p. 155).

Observa-se que as questões orientadoras da reflexão enfatizam a valorização e o respeito à diversidade, correspondendo aos objetivos de formação apontados pelo Relatório Jacques Delors. À primeira vista, essa afirmação, ou melhor, a perspectiva de formação que está na sua base, mostra-se como uma diretriz para a formação de sujeitos respeitosos em relação aos seus pares. Todavia, levada às suas últimas consequências, ela se alicerça na ideia segundo a qual, ao invés de alçar uma formação voltada para a luta contra as desigualdades sociais, como propunham as teorias críticas, a escola toma para si a responsabilidade de formar cidadãos que respeitam as diferenças, nomeadas como diversidade.

Elimina-se a discussão sobre diferença de classes. Exalta-se o respeito à diversidade. Nas imagens em que as baianas, os seringueiros e os trabalhadores da indústria são apresentados como exemplos da "diversidade" a ser valorizada e preservada, como formas sociais e culturais de ser e viver, é eliminada a possibilidade de a escola contribuir para o entendimento de que esses trabalhadores fazem parte de uma única classe, apesar de viverem em regiões distintas e de realizarem atividades também diferentes. Descarta-se a possibilidade de compreensão da totalidade, de ver no singular a manifestação do universal. Assim, aquilo que uniria os homens para lutar pela transformação das condições objetivas que geram as desigualdades, diluise em meio à valorização da "diversidade social e cultural". Nesse sentido, o respeito à diversidade significa a defesa da manutenção da sociedade de classes e, mais do que isso, o desejo de harmonia entre as classes. Ou seja, a Educação estaria, assim, contribuindo para "o desenvolvimento do querer viver juntos, elemento básico da coesão social e da identidade nacional" (DELORS, 1996, p. 59), correspondendo às orientações prescritas pelo Relatório Jacques Delors. 
Observa-se que termos como transformação social, lutas de classe, contradições desaparecem dos debates educacionais marcados por uma perspectiva neoliberal. No lugar deles passam a desfilar termos como: coesão social, solidariedade, equidade, harmonia. Isso não significa apenas a atualização de vocabulário, mas a mudança de conceito. Falar em transformação social implica ações no sentido de alterar a sociedade cuja base é a relação entre classes desiguais. Contrariamente, primar pela coesão social é justamente defender a permanência dessa sociedade.

Para Moraes (2001), esse fenômeno, denominado por ela de um "sutil exercício lingüístico" que se faz presente nos documentos oficiais e nas pesquisas em Educação, compõe um horizonte ideológico apaziguado.

Termos e conceitos têm sido absorvidos pela pragmática retórica corrente. Uns foram naturalizados o capitalismo, por exemplo - alguns foram construídos, re-significados, modificados ou substituídos por outros mais convenientes. O termo igualdade, entre outros tantos exemplos, cedeu lugar à equidade, o conceito de classe social foi substituído pelo de status sócio-econômico, os de pobreza e riqueza pela peculiar denominação de 'baixo' e 'alto' ingressos sociais. Destinado a assegurar a obediência e a resignação públicas, o novo e pragmático vocabulário faz-se necessário para erradicar o que é considerado obsoleto e a criar novas formas de controle e regulação sociais. Alcançar o consenso é então fundamental, o que é efetivado com inegável sucesso, seja pela cooptação de intelectuais - tantos deles educadores -, bem como pela monocórdia repetição de um mesmo discurso reformista para a educação nos documentos das agências multilaterais e nas políticas de governo de vários países, notadamente na América Latina. (MORAES, 2001, p. 14).

Observa-se também que mesmo se tratando de educação escolar, não se fala em conhecimento; fala-se, isto sim, em saberes. O conhecimento remete à teoria, ao domínio de formas complexas de pensamento, para além de situações cotidianas. Valorizar o conhecimento implica considerar a escola como a instituição a qual cabe permitir a todos aqueles que a frequentam o acesso ao conhecimento universal, fruto das conquistas da humanidade; justamente o saber que permite ao sujeito alcançar um patamar mais elevado em termos de compreensão dos fenômenos, sejam eles naturais, sociais, políticos, econômicos, etc., ou seja, elevar o pensamento "[...] até o ponto atingido pelo pensamento mundial mais evoluído". (GRAMSCI, 1999 apud DUARTE, 2006, p. 618).

Quando se admite que todos os saberes têm o mesmo valor e que, portanto, todos devem fazer parte do currículo escolar, como forma de respeito às diferenças culturais, acaba-se destituindo a esco- la da sua função, suprimindo o direito daqueles que têm a escola como a única possibilidade de acesso ao saber universal.

A ênfase no respeito à diversidade traz como consequência ações no sentido de afirmar as desigualdades que embora sejam vistas como individuais, são desigualdades sociais. Enquanto se falava em desigualdade social, procuravam-se formas para combatê-la e a forma mais razoável seria a transformação social. Quando, no lugar da luta contra a desigualdade, se instala a defesa da diversidade, instaura-se uma prática do "respeito" às diferenças. Desigualdade combate-se com transformação; respeito às diferenças conquista-se por meio da manutenção da sociedade. Nesse contexto, proliferam-se discursos em prol da pluralidade cultura. Diz-se que cada grupo social tem uma identidade própria que precisa ser mantida e respeitada; defende-se que cada grupo tem uma cultura própria, um saber particular, valores e costumes diversos dos de outros grupos. É como se o sujeito que vive em condições precárias em favelas, por exemplo, tivesse escolhido viver dessa forma porque faz parte de sua "cultura". O Brasil é visto como o país da diversidade cultural. Dadas as "diferenças culturais", alguns vivem em residências confortáveis, utilizam meios de transporte adequados, realizam viagens culturais; outros vivem em encostas, utilizam meios precários de locomoção, limitam-se ao conhecimento proporcionado pelas situações cotidianas. Isso é visto, simplesmente, como diversidade cultural e não como manifestações da desigualdade social. Ao não considerar as contradições da sociedade capitalista nesse contexto, oficializa-se o que Duarte denuncia como a "defesa do relativismo cultural e do discurso que faz da diversidade um princípio ético". (DUARTE, 2006).

$\mathrm{O}$ que estamos afirmando pode ser observado na matéria publicada pela Revista Nova Escola, intitulada "A favela como um espaço da cidade", especialmente no subtítulo "Pobreza material não significa miséria cultural". Essa matéria, cuja reflexão culmina com a apresentação de uma sequência didática destinada à $5^{\mathrm{a}}$ série, apresenta:

É importante que os estudantes também percebam que a favela não é um espaço isolado e caracterizado apenas por problemas socioeconômicos e de infraestrutura. "Por ser um ambiente multicultural, com pessoas vindas de diferentes lugares do país, esse espaços se tornaram condensadores de cultura", afirma Paulo Lins, poeta e autor do livro Cidade de Deus, que dedicou parte de sua vida a pesquisas antropológicas sobre o assunto. "Não à toa, certas manifestações que fazem parte da identidade cultural brasileira, como o samba e o pagode, têm seus maiores expoentes vindos justamente das comunidades. O rap, o funk e mesmo a religiosidade afro-brasileira, como a umbanda e o candomblé, também floresceram lá. Pobreza material não significa pobreza cultural", complementa. 
Diversidade é um conceito presente a todo momento nas discussões sobre os bolsões de moradias irregulares. É necessário explorar também o fato de que elas não são todas iguais. "No Norte e no Nordeste do país, existem comunidades erguidas sobre palafitas por causa de cheias dos rios e de mangues. E podem existir tipos diferentes de casa: de alvenaria e de madeirite, por exemplo", afirma Antonia dos Santos Garcia, mestre em Geografia pela Universidade Federal da Bahia. (MARTINS, 2009, p. 61)

A sugestão de trabalho trazida por esse periódico representa a objetivação pedagógica decorrente das concepções de cultura e escola que permeiam as atuais políticas educacionais. Essas concepções, porém, não se limitam a esse âmbito de debate. Pesquisas acadêmicas no campo educacional também oferecem subsídios para que sugestões de práticas pedagógicas dessa natureza se materializem no contexto escolar. A afirmação de Moreira e Candau (2008), exposta a seguir, mesmo que movida por outras intenções, oferecem a justificativa para esse tipo de atuação da escola:

Ainda, é inegável a pluralidade cultural do mundo em que vivemos e que se manifesta, de forma impetuosa, em todos os espaços sociais, inclusive nas escolas e nas salas de aula. Essa pluralidade freqüentemente acarreta confrontos e conflitos, tornando cada vez mais agudos os desafios a serem enfrentados pelos profissionais da educação. No entanto, essa mesma pluralidade pode propiciar o enriquecimento e a renovação das possibilidades de atuação pedagógica. (MOREIRA; CANDAU, 2008, p. 20).

Que as desigualdades sociais acabam levando grupos sociais a terem diferentes interações com a cultura e com a realidade de modo geral, conduzindo os sujeitos a diferentes formas de pensar e atuar no espaço escolar é, de fato, um conhecimento necessário aos profissionais da Educação. Portanto, são significativas as contribuições de pesquisas que desnudam a relação entre os diferentes contextos em que os estudantes vivem e a sua interação com o conteúdo escolar. Os conhecimentos produzidos por essas pesquisas sinalizam que os alunos possuem diferentes motivos para o estudo, apresentam divergentes pontos de partida em relação ao conhecimento sistematizado, além de serem donos de saberes que podem e devem adentrar a sala de aula. Não há como negar que esses conhecimentos são importantes para o professor proceder à organização didática da atividade de ensino, pois assim poderá levar em conta a realidade dos alunos, criando os elos necessários, conforme cada contexto, para que todos, com maior ou menor proximidade com a cultura escolar, cheguem a dominar o conhecimento científico. Em outras palavras: a realidade do aluno deve ser considerada, quando menos, por duas razões: a) ela informa sobre os motivos de estudo do aluno e seus possíveis conhecimentos prévios - o que é fundamental para o professor organizar didaticamente a introdução de novos conhecimentos; b) o aluno deve conhecer a própria realidade, porém, não de maneira empírica, pela atuação imediata, mas de modo teórico. Isso quer dizer que a realidade deve ser objeto de estudo; mas de um estudo mediado pelo conhecimento científico, o que, muitas vezes, significa afastar-se da realidade para adquirir os instrumentos simbólicos que permitem ir além da aparência dos fenômenos.

Não se trata, portanto, de transformar o próprio saber do aluno e de sua comunidade em conteúdo escolar para valorizá-los, num movimento que conduz à adaptação social. Trata-se de ter essa realidade e esses saberes como referência com vistas à conscientização e à transformação social quando essa realidade não for apenas diferente, mas basicamente desigual.

\section{Considerações Finais}

Ao longo deste artigo buscamos desvelar a sintonia entre a perspectiva de formação defendida por documentos oficiais que orientam a Educação Básica, bem como as práticas pedagógicas que eles sugerem, apontando a relação entre uma política pública de definição curricular e a organização didática do conteúdo escolar. Destacamos que são apontadas duas faces de uma mesma perspectiva de formação: uma voltada para o desenvolvimento de capacidades e competências para que os sujeitos tenham condições de atuar no mercado de trabalho; outra voltada para a formação de valores e atitudes frente às novas formas de sociabilidade que emergem no contexto da sociedade globalizada.

Observamos que dentre os quatro pilares da aprendizagem apresentados pelo Relatório Jacques Delors e assumidos pelos PCN o destaque maior é dado ao "aprender a aprender" e ao "aprender a viver juntos", que representam, de forma mais enfática, a perspectiva de formação já apontada. Em livros didáticos de diferentes áreas do conhecimento, bem como em periódicos especializados - nos quais encontramos indícios da prática pedagógica - essas novas aprendizagens manifestam-se nos conteúdos e sugestões de atividades por eles sistematizados. Neles, são destacados temas que têm por finalidade transmitir valores e atitudes de (ou ligados a) cidadania, respeito, aceitação, convivência, tolerância, solidariedade, autonomia, democracia, liberdade, dentre outros. Temas que, diante das desigualdades sociais, afirmam a necessidade de valores e atitudes como um meio de manter a coesão social.

Pode-se, porém, considerar esses temas como conteúdos importantes a serem trabalhados 
na escola, a despeito de serem utilizados como meios de desenvolver nos alunos atitudes e valores que concorram para a reprodução do capital. Nesse caso, convém destacar o alerta feito por Manacorda (1986, p. 60):

\begin{abstract}
Uma educação voltada apenas para a afirmação dos princípios de liberdade, democracia, participação cultural, é sempre inadequada. Não basta. Porque tal gênero de educação os inimigos da democracia também podem fazer, no plano do discurso. Sem negar esses princípios ou ignorá-los, considero mais importante que os homens sejam instruídos, isto é, armados de saber, de tal modo que possam participar concretamente da criação de uma vida mais rica, de uma maior capacidade produtiva, com maior participação democrática. Isto significa mais instrução, mais cultura.
\end{abstract}

O que à primeira vista pode parecer um avanço, à medida que busca incluir novas aprendizagens, romper com práticas conteudistas consideradas tradicionais e praticar o respeito à diversidade cultural significa a oficialização de uma Educação que, em nome da inclusão e mediante o desenvolvimento de competências e habilidades exigidas pelo mundo globalizado, exclui a possibilidade e o compromisso de a escola realmente contribuir para o desenvolvimento cognitivo de todos os sujeitos, uma vez que deixa de priorizar a condição para esse desenvolvimento: o acesso ao conhecimento científico. Com isso, ao invés de uma escola "assentada no conhecimento", vislumbra-se a escola para o acolhimento social, ou seja, a escola que prima por "[...] formas de organização das relações humanas, nas quais prevalecem a integração social, a convivência entre diferentes, o compartilhamento de culturas, o encontro e a solidariedade entre as pessoas". (LIBÂNEO, 2010, p. 4). Trata-se, enfim, de uma escola que não tem como prioridade o desenvolvimento intelectual dos estudantes.

\section{Referências}

BRASIL. Lei no 9.394/96 de 20 de dezembro de 1996. Estabelece as diretrizes e bases da educação nacional. Diário Oficial da União, Brasília, 23 dez. 1996.

Secretaria de Educação Fundamental. Parâmetros Curriculares Nacionais: Meio Ambiente, Saúde. Brasília: MEC/SEF, 1997a. (Ensino de $1^{\mathrm{a}}$ à $4^{\mathrm{a}}$ série).

Secretaria de Educação Fundamental. Parâmetros Curriculares Nacionais: introdução aos Parâmetros Curriculares Nacionais. Brasília: MEC/SEF, 1997b. (Ensino de $1^{\mathrm{a}}$ à $4^{\mathrm{a}}$ série).

Secretaria de Educação Fundamental. Parâmetros Curriculares Nacionais: Matemática. Brasília: MEC/SEF, 1997c.
Secretaria de Educação Fundamental. Parâmetros Curriculares Nacionais: matemática. Brasília: MEC/SEF, 1998a.

Secretaria de Educação Fundamental. Parâmetros Curriculares Nacionais: $3^{\circ}$ e $4^{\circ}$ ciclos do Ensino Fundamental: introdução aos Parâmetros Curriculares Nacionais. Brasília: MEC/SEF, 1998b.

PNDL 2004 - Guia de livros didáticos: História e Geografia. 1ª a $4^{a}$ Séries, v. 3. Brasília: MEC, 2002. Disponível em: <http://portal.mec.gov.br/seb/ arquivos/pdf/guia3.pdf>. Acesso em: 29 maio 2010.

CASTRO, T. C. Nosso mundo: História e Geografia $4{ }^{\mathrm{a}}$ série. São Paulo: Ática, 2004.

CURY, C. R. J. A educação básica no Brasil. Educação \& Sociedade, Campinas, v. 23, n. 80, p. 169-201, set. 2002. DOI: $10.1590 / S 0101-73302002008000010$

DELORS, J. (Org.). Educação: um tesouro a descobrir. Relatório para a UNESCO da Comissão Internacional sobre Educação para o século XXI. Lisboa: Edições Asa, 1996.

DUARTE, N. A contradição entre universalidade da cultura humana e o esvaziamento das relações sociais: por uma educação que supere a falsa escolha entre etnocentrismo ou relativismo cultural. Educação e Pesquisa, São Paulo, v. 32, n. 3, p. 607-618, set./dez. 2006. DOI: 10.1590/S1517-97022006000300012

FREITAS, L. C. A internalização da exclusão. Educação \& Sociedade, Campinas, v. 23, n. 80, p. 301-327, set. 2002. DOI: 10.1590/S0101-73302002008000015

GALLO, S. D. Parâmetros Curriculares Nacionais para o ensino fundamental: entre o oficial e o alternativo. Comunicações: Revista do PPGE-Unimep, Piracicaba, v. 11, n. 1, p. 17-27, jun. 2004.

GALUCH, M. T. B. Experiência e práticas docentes: o ensino de ciências nas séries iniciais do ensino fundamental. 2004. 100 f. Tese (Doutorado em Educação) - Pontifícia Universidade Católica de São Paulo, São Paulo, 2004

GIMENO SACRISTÁN, J. O currículo: os conteúdos do ensino ou uma análise prática? In: GIMENO SACRISTÁN, J.; PÉREZ GÓMEZ, A. I. Compreeender e transformar o ensino. Porto Alegre: Artmed, 2000.

HARVEY, D. Condição Pós-Moderna: uma pesquisa sobre as origens da mudança cultural. 10. ed. São Paulo: Loyola, 2001.

LIBÂNEO, J. C. A escola brasileira em face de um dualismo perverso: escola do conhecimento para os ricos, escola do acolhimento social para os pobres. Goiânia: PUC-GO, 2010. Disponível em: <http://professor.ucg.br/SiteDocente/admin/arquivosUpload/5146/ material/SEMANA\%20DE\%20PLANEJ\%20PUC\%20 AGO\%202010\%20FINAL.doc>. Acesso em: 20 jan. 2011.

LOPES, A. C. Os parâmetros curriculares nacionais para o ensino médio e a submissão ao mundo produti- 
vo: o caso do conceito de contextualização. Educação \& Sociedade, Campinas, v. 23, n. 80, p. 389-403, set. 2002. DOI: $10.1590 / S 0101-73302002008000019$

MANACORDA, M. Depoimento. Revista Ande, São Paulo, n. 10, p. 59-64, 1986.

MARCUSE, H. A ideologia da sociedade industrial. 5. ed. Rio de Janeiro: Zahar Editores, 1979.

MARTINS, A. R. A favela como um espaço da cidade. Revista Nova Escola, São Paulo, n. 223, jun. 2009.

MORAES, M. C. M. de M. Recuo da teoria: dilemas da pesquisa em educação. Revista Portuguesa de Educação, Braga, v. 14, n. 1, p. 7-25, 2001.

MOREIRA, A. F. B.; CANDAU, V. M. Indagações sobre currículo: currículo, conhecimento e cultura. In: BEAUCHAMP, J.; PAGEL, S. D.; NASCIMENTO, A. R. do. (Org.). Indagações sobre currículo. Brasília: Ministério da Educação, Secretaria de Educação Básica, 2007.

PALANGANA, I. C. Individualidade: afirmação e negação na sociedade capitalista. São Paulo: Summus, 1998.

SAVIANI, D. História das ideias pedagógicas no Brasil. Campinas: Autores Associados, 2007.

SFORNI, M. S. de F.; CASCONE, O. B. Avaliação e adoção do livro didático: do currículo prescrito ao currículo em ação. In: COLÓQUIO SOBRE QUESTÕES CURRICULARES, 9.; COLÓQUIO LUSO-BRASILEIRO, 5., 2010, Porto. Anais... Porto: Universidade do Porto, 2010. p. 2666-2676.

SILVAJR., J. dos R. Mudanças estruturais no capitalismo e a política educacional do governo FHC: o caso do ensino médio. Educação \& Sociedade, Campinas, v. 23, n. 80, p. 203-234, set. 2002.

DOI: 10.1590/S0101-73302002008000011

SINGER, P. Desenvolvimento capitalista e desenvolvimento solidário. Estudos avançados, São Paulo, v. 18 , n. 51 , p. 7-22, maio/ago. 2004. DOI: 10.1590/ s0103-40142004000200001

Recebido em 30/01/2011

Versão final recebida em 10/03/2011

Aceito em 05/04/2011 